\title{
The Graduate Business Student and the Library
}

\begin{abstract}
$\mathbf{R}$ Research on the graduate business student's knowledge, attitudes toward, and use of the library is rare. When one considers the alleged importance of the library as a source of business information and the increasing emphasis on research skills in business, the lack of research on the role of the library in the education of the graduate business student is surprising. ${ }^{1}$
\end{abstract}

There is general agreement with A. M. Cartter's assertion that, "The library is the heart of the University; no other single nonhuman factor is as closely related to the quality of graduate education." ${ }^{2}$ While there seems to be a philosophical consensus that this premise is a necessary and desirable goal, in fact, casual observation tends to make this statement seem a mere platitude. Certainly, any assumption concerning the actual role of the library in the education of graduate business students is subject to much closer examination.

The basic objective of this research was to examine the aforementioned situation. It was as an exploration into an area where research was long overdue. The research had three purposes: (1)

Drs. Lee and Read are associate and assistant professors of management at the Florida State University, Tallahassee.

The critical comments and suggestions of Dr. Louis Shores are gratefully acknowledged by the authors. to examine the graduate business student's knowledge of the library, (2) to explore the graduate business student's attitude toward the library, and (3) to secure some indication of his use of the library.

\section{Methodology and SubJects}

The data for this study were obtained by administering a twenty-two item questionnaire to three graduate business classes at a large accredited southeastern business school. ${ }^{\circ}$ Seventy-nine graduate business students returned the two part questionnaire which took approximately twenty minutes to complete.

The convenience sample consisted of fifty management majors, fourteen marketing majors, eight finance majors, six accounting majors, and one quantitative methods major. Three respondents were DBA candidates.

Eight of the questions utilized a "Likert-type" format consisting of five responses (strongly agree, agree, undecided, disagree, strongly disagree; or very poor, poor, average, good, excellent). Of the remaining questions, three required a simple "yes" or "no" response while eight required the naming of specific library sources that the student would consult to obtain specified information. Three questions were openended in nature seeking attitudes and opinions.

- A copy of the questionnaire will be provided by the authors on request. 


\section{Student Knowledge of THE BusIness} Library-A Self Appraisal

The first part of the questionnaire required the graduate business student to appraise his knowledge of the library along with the knowledge of his fellow graduate students and college students in general. Additionally, two questions were included to ascertain where and how the respondent acquired his knowledge of the library.

Sixty-five percent of the respondents felt that college students do not know how to use the library effectively. Of the remainder, 21 percent were undecided while 13 percent thought that students knew how to use library resources effectively.

When the respondents were asked to assess the ability of graduate business students to utilize the library, 48 percent held the view that graduate business students could not utilize the library well. The same 13 percent who thought college students in general could effectively utilize the library were the same respondents who felt graduate business students knew how to use the library; the remainder were unsure.

Students were then given an opportunity to rate their own knowledge of the library prior to actually being tested for competency. Nine percent rated their knowledge as very poor, 22 percent rated their knowledge poor, and 43 percent of the graduate students rated their knowledge as average. Only 25 percent of the respondents rated their knowledge good or excellent. While these ratings do not seem extraordinarily high, test results proved these ratings to be grossly overestimated.

Finally, inquiries pertaining to where or how the student acquired his knowledge of the library revealed that none of the students had ever received any formal classroom instruction on use of the library. A significant 82 percent of the respondents reported that they had done no independent reading to im- prove their knowledge of how to use the library.

\section{Tested KNOWLEDGE OF THE BusinESS LiBRARY}

After the student had completed the first part of the questionnaire covering library usage, knowledge ratings, and attitudes, he was given a fill-in questionnaire (which consisted of six specific questions) requesting him to identify specific sources (indices, abstracts, or publications) which he would consult to obtain certain information. Topics for which the student was requested to list library sources were: the top 100 industrial firms in the United States in 1970; a review of Toffler's Future Shock; disposable personal income; and so forth. One question asked for a listing of the indices and/or abstracts in the library that the student felt competent to use. Another important question required the student to outline the exact research strategy he would develop to compile an annotated bibliography on the subject of management development.

On the first set of questions, 25 percent of the students were unable to indicate a single suitable source for obtaining information on any of the six subjects given. Only 37 percent of the respondents were able to answer correctly more than one question; 48 percent of the graduate students could not list one index or abstract that they knew how to use. Only 11 percent of the respondents were able to list more than two sources that they knew how to use.

In scoring the answers to the question requiring the student to outline the exact strategy for the annotated bibliography, grades on a scale of 0 to 5 were subjectively assigned depending upon the adequacy of the student's research procedure. The results showed that 47 percent of the graduate students scored 0 ; another 47 percent scored 1 ; and the remaining 6 percent scored 2 . No one re- 
ceived a score higher than 2 . The dismal performance of the respondents on this part of the test was at first attributed to unrealistic expectations on the part of the graders. A subsequent review of the results, however, did not alter the original ratings. Without exception, these graduate business students did not know how to compile an adequate bibliography on such a mundane topic as management development.

\section{Self Rating of KNowledge- A ReApPraisal}

Immediately after the first testing of the respondent's knowledge of the library, the students were asked to rate their knowledge of the library a second time. The purpose of this rerating was to determine what effects, if any, the test for competency had had upon the student's analysis of his proficiency in using the library. Significantly, 55 percent of the students now rated their knowledge as poor or very poor (an increase from 31 percent for the same question asked prior to the actual testing for knowledge), 30 percent rated their knowledge average (a decrease from 43 percent), and only 15 percent maintained a self-appraisal of good or excellent (a decrease from 25 percent).

When one considers that 42 percent of the students had actually lowered their self-appraisal by either one or more levels of proficiency, it is not difficult to ascertain the effect that the student's own performance on the first test had on his view of his own skills. Moreover, not one respondent raised his selfappraisal after completing both parts of the questionnaire. Obviously the students had not impressed themselves with their display of knowledge.

However, even in light of the more realistic reappraisal, the students' view of their library skills remained considerably greater than could be justified when test results were analyzed. This may in part be due to the fact that the test results were not disclosed prior to the rerating. Their poor performance on test questions which required a display of library knowledge, plus their tendency to lower their own ratings after attempting to answer relatively simple questions, is ample testimony to both their lack of proficiency and, in some cases, their unawareness of the extent of their deficiencies.

\section{Library USAGe and Confidence}

Students were asked to estimate the number of times they made use of the library in an average month. Approximately 67 percent of the students reported that they used the library six or more times a month, while 18 percent indicated that they used the library between one and five times a month. A surprising 15 percent of the students noted that they did not use the library at all.

A reexamination of the open-ended questions revealed that the library was used in part as a place to study or to socialize between classes. The purposes of library use were not obtained by the instrument, but follow-up interviews with eight of the students who had indicated they used the. library six or more times a month found that they made extensive use of the library to study, not to do research. The interviews with the students seemed to support Lyle's observation that students still regard libraries as places for studying their own texts, for meeting friends, or for lounging. ${ }^{3}$

It was particularly significant to note that 53 percent of the students surveyed had never used the library for research other than class assignments. When one considers the current emphasis on independent study and individualized instruction, the absence of library utilization, except when required, raises serious questions about the capacity of the graduate business student to engage in independent study. Conversely, questions must be raised about the extent to 
which the library is integrated into the business curriculum.

Student opinions of their library knowledge were correlated with their usage. The ratings presented a consistent pattern, in that high usage was correlated with high self-ratings of library knowledge and low library knowledge ratings with low usage.

Another area studied was perceived library knowledge and its relationship to the students' completion of a graduate business research course. This course requires a considerable amount of library research. Correlations were done between two groups of students: those who had previously taken the research methods course and those who had not. The results showed that among those who had taken the research course, 67 percent rated their knowledge as good to excellent while 33 percent rated their knowledge as poor to very poor. Among those who had not taken the research course, only 34 percent rated their knowledge as good to excellent, while 66 percent rated their knowledge as poor to very poor.

All of the students, irrespective of their length in the program, who had not taken the research course, rated their knowledge of the library, poor or very poor. This analysis suggested that a high degree of confidence in use of the business library was instilled in students who had completed the research methods course. It also presumed that length of time in the program, by itself, was not an important variable. Unfortunately, additional analysis of the questionnaire results revealed that the confidence instilled by the research methods course was not justified. In other words the test results indicated that students having completed the research course were not more knowledgeable than the students who had not taken the course. Thus, confidence in one's ability to use the library is not necessarily an indication of one's real ability.

\section{Student AtTitudes Toward THE LIBRARY}

Student attitudes toward the business library were ascertained through three questions. The first question was openended requiring the respondents to name the first thing that came to mind when he thought of the business library.

Comments to this open-ended question were varied. The responses fell into these categories: physical conditions, utilization of facilities, and general statements concerning the library. Approximately one-third of the responses to this question were negative in that they focused upon facility problems or the difficulties that students experienced in using the library.

Student opinions were solicited on the role the business library presently plays in the education of graduate business students. Seventy-five percent of the students strongly agreed or agreed with the statement that the library plays an important role while 9 percent were undecided as to the role of the library. The business library was felt to be capable of playing an important role in the education of graduate business students by 90 percent of the students. An analysis of the strongly agree responses for both questions found a substantial change of approximately 25 percent. It would seem reasonable to conclude that the graduate business student recognizes not only the importance of the library to his program of study, but the potentially greater role that it could and should play.

\section{Conclusions}

A recent study of undergraduate business students found their knowledge of the library to be quite deficient. ${ }^{4}$ It can be seen from the results of this study that the same conclusion is warranted for the graduate students. The graduate business student is, by his own admission, ill-prepared to use the library effectively in his course of study. Test re- 
sults were consistent in that the scores confirmed the students' perceived lack of knowledge. In fact, test results indicated that a majority of students rated their knowledge higher than warranted. While the graduate business student may be better prepared to use the library than the undergraduate business student, his level of knowledge is still inadequate. This is particularly disturbing since an executive's knowledge of the literature of his field and his skill in its use are important factors determining his professional advancement and competence.

There exists a clear need to review the role of the library in the formal education of graduate business students. It is ironic that such a gap exists between the potential role of the library and its present role. The present "sink-or-swim" approach to developing library skills is a proven unsatisfactory method. Students do not acquire library knowledge by "osmosis" nor by guided tours. It is also somewhat disheartening to note that an overwhelming majority of the graduate students do not take the time to build their library skills through independent study.

The negative attitude evidenced by one-third of the students is not an inconsistent finding, considering the difficulties they face in utilizing the resources of the library. It is quite possible that this negative attitude would not exist if proper instruction in the use of library resources could be provided early in the graduate business program. However, it may also be possible that, at present, most members of business faculties are themselves too deficient in library skills to answer the challenge.

\section{REFERENCES}

1. John Bruner and John W. Lee, "Student Knowledge, Attitude and Use of the Business Library," The Research Committee Working Paper No. 19, Data Analysis Center, The Florida State University.

2. Allan M. Cartter, An Assessment of Quality in Graduate Education (Washington, D.C.: American Council on Education, 1966), p. 114.

3. Guy R. Lyle, The President, the Professor and the College Library (New York: H. W. Wilson Co., 1963).

4. Bruner, "Student Knowledge, Attitude..., ," 